\title{
Cognitive Load Theory: Implications for medical education: AMEE Guide No. 86
}

Citation for published version (APA):

Young, J. Q., Van Merrienboer, J., Durning, S., \& Ten Cate, O. (2014). Cognitive Load Theory: Implications for medical education: AMEE Guide No. 86. Medical Teacher, 36(5), 371-384. https://doi.org/10.3109/0142159X.2014.889290

Document status and date:

Published: 01/05/2014

DOI:

10.3109/0142159X.2014.889290

Document Version:

Publisher's PDF, also known as Version of record

Document license:

Taverne

Please check the document version of this publication:

- A submitted manuscript is the version of the article upon submission and before peer-review. There can be important differences between the submitted version and the official published version of record.

People interested in the research are advised to contact the author for the final version of the publication, or visit the DOI to the publisher's website.

- The final author version and the galley proof are versions of the publication after peer review.

- The final published version features the final layout of the paper including the volume, issue and page numbers.

Link to publication

\footnotetext{
General rights rights.

- You may freely distribute the URL identifying the publication in the public portal. please follow below link for the End User Agreement:

www.umlib.nl/taverne-license

Take down policy

If you believe that this document breaches copyright please contact us at:

repository@maastrichtuniversity.nl

providing details and we will investigate your claim.
}

Copyright and moral rights for the publications made accessible in the public portal are retained by the authors and/or other copyright owners and it is a condition of accessing publications that users recognise and abide by the legal requirements associated with these

- Users may download and print one copy of any publication from the public portal for the purpose of private study or research.

- You may not further distribute the material or use it for any profit-making activity or commercial gain

If the publication is distributed under the terms of Article $25 \mathrm{fa}$ of the Dutch Copyright Act, indicated by the "Taverne" license above, 


\section{Cognitive Load Theory: Implications for medical education: AMEE Guide No. 86}

John Q. Young, Jeroen Van Merrienboer, Steve Durning \& Olle Ten Cate

To cite this article: John Q. Young, Jeroen Van Merrienboer, Steve Durning \& Olle Ten Cate (2014) Cognitive Load Theory: Implications for medical education: AMEE Guide No. 86, Medical Teacher, 36:5, 371-384, DOI: 10.3109/0142159X.2014.889290

To link to this article: https://doi.org/10.3109/0142159X.2014.889290

\section{Published online: 04 Mar 2014.}

Submit your article to this journal $\sqsubset$

Џll Article views: 11136

Q View related articles $\asymp$

View Crossmark data ¿

Citing articles: 152 View citing articles $\sqsubset$ 


\title{
Cognitive Load Theory: Implications for medical education: AMEE Guide No. 86
}

\author{
JOHN Q. YOUNG ${ }^{1}$, JEROEN VAN MERRIENBOER ${ }^{2}$, STEVE DURNING ${ }^{3}$ \& OLLE TEN CATE ${ }^{4}$ \\ ${ }^{1}$ Hofstra North Shore-LIJ School of Medicine, USA, ${ }^{2}$ Maastricht University, The Netherlands, ${ }^{3}$ Uniformed Services University \\ of the Health Sciences, USA, and ${ }^{4}$ Center for Research and Development of Education, The Netherlands
}

\begin{abstract}
Cognitive Load Theory (CLT) builds upon established models of human memory that include the subsystems of sensory, working and long-term memory. Working memory (WM) can only process a limited number of information elements at any given time. This constraint creates a "bottleneck" for learning. CLT identifies three types of cognitive load that impact WM: intrinsic load (associated with performing essential aspects of the task), extraneous load (associated with non-essential aspects of the task) and germane load (associated with the deliberate use of cognitive strategies that facilitate learning). When the cognitive load associated with a task exceeds the learner's WM capacity, performance and learning is impaired. To facilitate learning, CLT researchers have developed instructional techniques that decrease extraneous load (e.g. worked examples), titrate intrinsic load to the developmental stage of the learner (e.g. simplify task without decontextualizing) and ensure that unused WM capacity is dedicated to germane load, i.e. cognitive learning strategies. A number of instructional techniques have been empirically tested. As learners' progress, curricula must also attend to the expertise-reversal effect. Instructional techniques that facilitate learning among early learners may not help and may even interfere with learning among more advanced learners. CLT has particular relevance to medical education because many of the professional activities to be learned require the simultaneous integration of multiple and varied sets of knowledge, skills and behaviors at a specific time and place. These activities possess high "element interactivity" and therefore impose a cognitive load that may surpass the WM capacity of the learner. Applications to various medical education settings (classroom, workplace and self-directed learning) are explored.
\end{abstract}

\section{Introduction}

Successful learning requires the interplay of multiple processes, including those in the cognitive, affective (i.e. motivation and emotion), social (i.e. interaction with and experience of others), environmental (i.e. location or setting) and metacognitive (i.e. thinking about one's thinking) domains. Given the complexity of learning, it is not surprising that many, sometimes competing and often overlapping theories of learning have been put forward. Schunk (2012) recently categorized learning theories into neuroscience, behaviorism, social cognition, information processing, constructivism, cognitive learning, motivation, self-regulation and development (Schunk 2012). With the plethora of theories arising from disparate academic disciplines, the vocabulary can be obtuse and the arguments intense.

The debates around learning theories can be reminiscent of the story of the elephant and the six blind men (Mallisena et al. 1933). The six blind men were asked to determine what an elephant looked like by feeling different parts of the elephant's body. They of course came to very different conclusions. The blind man who feels a leg says the elephant is like a pillar; the one who feels the tail says the elephant is like a rope; the one who feels the trunk says the elephant is like a tree branch; the one who feels the ear says the elephant is like a hand-held fan; the one who feels the belly says the elephant is like a wall; and the one who feels the tusk says the elephant is like a solid pipe. Resolution to the conflict only occurs when an "enlightened one" points out that each is describing one part of the whole. Similarly, in medical education, we have multiple theories. Each captures a "part of the whole". However, no "enlightened one" or unifying theory of learning has (yet) emerged. Therefore, educators must select from amongst these theories and then adapt and apply them as appropriate.

Cognitive Load Theory (CLT), first described by John Sweller in 1988 (Sweller 1988), represents an important cognitive learning theory, which is receiving increasing recognition in medical education. CLT integrates three key components of the cognitive architecture: memory systems (sensory, working and long-term memory; LTM), learning processes and types of cognitive load imposed on working memory (WM). CLT has particular relevance to medical education because the tasks and professional activities to be learned require the simultaneous integration of multiple and varied sets of knowledge, skills and behaviors at a specific time and place. These tasks may overload the learner. CLT helps us understand how and why learners in the health professions struggle with mastering the complex concepts and developing toward expertise. CLT has also generated new instructional approaches that hold promise (van Merriënboer \& Kirschner 2013). This guide will help medical educators understand CLT and how it can be used to optimize learning. We will 


\section{Practice points}

- Cognitive Load Theory (CLT) builds upon an established model of human memory that includes the subsystems of sensory, working and long-term memory.

- Working memory (WM) can only process seven elements of information at any given time. This constraint creates a "bottleneck" for learning.

- CLT delineates three types of cognitive load that impact WM: intrinsic (essential to the task), extraneous (not essential to the task) and germane (load imposed by the learner's deliberate use of cognitive strategies to facilitate learning, i.e. schemata construction).

- When the cognitive load associated with a task exceeds the learner's WM capacity, performance and learning is impaired.

- CLT has particular relevance to medical education because the tasks are complex and may impose a cognitive load that surpasses the WM capacity of the learner.

- To facilitate learning, CLT focuses on instructional techniques that decrease extraneous load (e.g. worked examples), titrate intrinsic load to the developmental stage of the learner (e.g. simplify task without decontextualizing) and ensure that unused WM capacity is dedicated to germane load, i.e. cognitive strategies that facilitate learning.

- CLT is also consistent with an approach to curricular design called 4C/ID, which includes several important elements: authentic learning tasks, supportive information that is adapted to the expertise of the learner, feedback and opportunities for part-task practice as necessary.

summarize CLT and the cognitive architecture it assumes and then explore how CLT informs instructional technique and curriculum design in medical education.

\section{CLT and the human memory system}

CLT is about memory and builds upon a pre-existing model of human memory developed by Atkinson and Shiffrin in the 1960s (Atkinson \& Shiffrin 1968). Figure 1 depicts how the three components of memory proposed by the Atkinson and Shiffrin model relate to each other. In short, information enters the mind through the sensory memory system. This sub-system can simultaneously process huge amounts of visual and auditory information, but retains the information only for a very short period of time (milliseconds). Information raised to awareness enters the domain of WM. WM (re-)organizes the information so that it may be efficiently stored as packages in LTM. The LTM has theoretically limitless capacity in terms of duration and volume, but a route map is required to find the information. The WM encodes the information with this route map to enable retrieval when the information is needed in the future.

Unlike sensory memory and LTM, WM is not infinite. In a famous 1956 article, Miller postulated that the WM cannot process more than about seven independent units at a time (Miller 1956), an assertion that subsequent research has confirmed. The arrows in Figure 1 show the flow of information.

\section{Sensory memory}

Learning progresses through distinctive pathways of the human memory system (Issa et al. 2011). This process starts with the sensory memory system. CLT is based on the dual channel principle-the notion that learners have separate channels for perceiving and processing auditory and visual information (Paivio 1986). In medical education, the majority of sensory information comes in the form of sounds (e.g. spoken words) and images (e.g. printed words and pictures), though touch and smell are also important. Printed words and pictures (e.g. graphs and facial expression of a patient) are perceived by the eyes and briefly held in the visual sensory memory system (also called iconic memory). Spoken words and other sounds (e.g. heartbeat and the patient's answer to a question) are perceived by the ears and briefly held in the auditory sensory memory system (echoic memory). The sensory memory system has enormous capacity-the visual and auditory systems perceive a vast amount of incoming information but can hold any given piece of information for only a very brief period of time (from less than 0.25 to 2 seconds) (Mayer 2010). Most of the perceived information does not reach conscious awareness. But when a learner attends to information in sensory memory, such as the words of an attending clinician describing the pathophysiology of congestive heart failure, the information moves to WM.

\section{Working memory}

A learner must have intact capacity for attention in order to "screen out" irrelevant stimuli (e.g. the bird chirping outside or a peer rustling through his backpack during a lecture) and "screen in" the relevant words and images (e.g. the patient's history or rash) from the sensory memory system for processing in the WM (Mayer 2010). As said, a learner's WM can hold no more than seven $( \pm 2)$ information elements at a time (Miller 1956) and can actively process (i.e. organize, compare and contrast) no more than two to four elements at any given moment (Kirschner et al. 2006). In addition, WM can only hold an information element for a few seconds with almost all information lost after 30 seconds unless it is actively refreshed by rehearsal (e.g. repeating to oneself an important laboratory value or phone number that one has verbally received until one is able to write it down). The limited capacity of WM has a profound impact on the rate of learning. Many learning tasks, especially complex clinical activities, entail more than seven units of information. For the learner to work within these constraints, all of the information elements must be combined and organized into a few meaningful units, also called "chunks". Information processing in WM refers to mentally rearranging the words and images into a coherent cognitive 


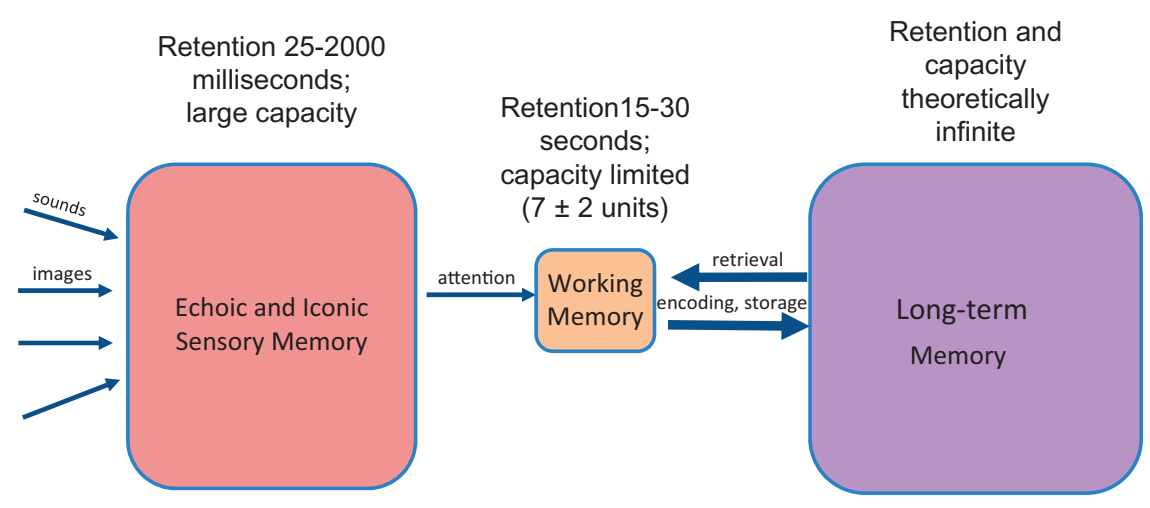

Figure 1. Aktinson-Shriffin three-stage model of human memory.

representation (or schema) and connecting this with relevant prior knowledge activated from LTM. This occurs, for example, when we construct the schema of chicken noodle soup after observing a bowl filled with a steaming yellow liquid with noodles and small bits of white meat or when the student examines the tracings of an ECG (visual images) and identifies normal sinus rhythm with ST elevation (a cognitive representation). In each case, multiple pieces of information are rearranged into one representation, which can then be activated in the WM as one single element.

Dual-channel theory places an additional constraint on WM-the auditory and visual channels for processing sensory information in the WM are partly independent of one another (Mousavi et al. 1995). This means that each channel has a predetermined limited capacity to process incoming information, i.e. one channel may be saturated while the other is not. It also means that limited WM capacity can be expanded by utilizing both channels rather than only one (Sweller et al. 1998). For example, the words in an online module that also includes multiple diagrams can be spoken rather than printed (e.g. on a slide) in order to offload information from the visual channel onto the auditory channel.

These limitations in WM capacity and duration are particularly evident when the information is novel to the learner-the absence of pre-existing "chunks" in LTM with which to organize the information means the learner's WM can easily be overwhelmed. In assessing a patient with angina, the new student's WM will be fully taxed simply by processing the different possible permutations or interactions of the patient's key symptoms: sub-sternal chest pain with shortness of breath and nausea that radiates to the left shoulder/arm and only occurs with exertion in the absence of fever or cough. A more experienced student will recognize the pattern and be able to "chunk" all of this information into the schema of "angina"- - a single element in WM rather than seven individual symptoms.

\section{Long-term memory}

Unlike WM, LTM is theoretically limitless in its capacity to store information. LTM holds cognitive schemata that vary in their degree of complexity and automation (van Merriënboer \& Sweller 2005, 2010). Schemata are domain-specific knowledge structures. A schema organizes multiple elements of information according to how those elements relate to each other and/or will be used. Illness scripts represent a type of schemata (Bowen 2006; Boshuizen \& Schmidt 1992); for example, the illness script for a major depressive episode organizes the various symptoms and signs into one construct. This reduces the number of individual information elements from nine or more (symptoms and signs) to one schema or chunk and helps the learner differentiate a major depressive episode from similar illnesses such as dysthymia. Thus, schemata organize knowledge in LTM and substantially reduce WM load because even a highly complex schema can be retrieved and processed as one information element in WM.

The analogy of a computer illustrates this concept. The computer's hard drive or its cloud-based server functions as LTM-it can store vast amounts of information. The amount of information that a computer can process at any given time is, however, determined by its random access memory-like WM in human memory. A computer's random access memory has much less capacity than its hard drive. If a computer was designed to mimic human memory, the computer's random access memory (WM) would be limited such that only seven documents could be open at once. When you opened an eighth document, one of the seven previously open documents would close. Each document stored on the hard drive or in the "cloud" is a schema-the quality and quantity of the information contained within each document varies. Some documents contain a large amount of information in a highly organized and precise format while others contain little information or information that lacks structure.

Figure 2 illustrates how WM manages three elements of information simultaneously while working to combine them into one chunk of information (bounded by the red circle), which is a schema or, in the setting of medical education, a special type of schema called an illness script. Meanwhile, the figure makes clear that two separate elements in LTM have been activated to link to the new piece of information. Each of these two has been composed in the past of several separate elements of information and stored in LTM.

\section{Implications for expertise}

Expertise does not come from a superior ability to analyze multiple pieces of novel information, from general problemsolving skills or from better WM. Rather, expertise is an 


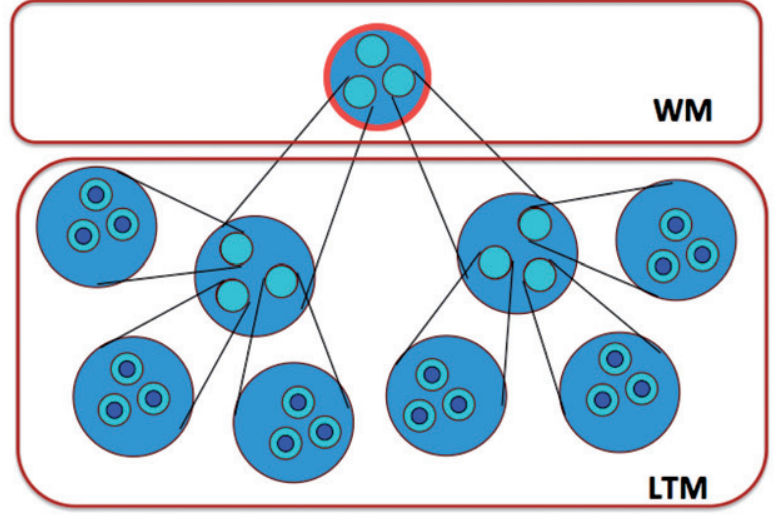

Figure 2. Chunking: Working memory creates a chunk of information by retrieving information elements from long-term memory that are chunks in themselves.

adaptation. It stems from the ability to efficiently recognize patterns or states by comparing what is perceived against the person's extensive domain knowledge that is stored in wellorganized schemata in LTM (Norman et al. 1985). Expertise is critically dependent on LTM. Research on chess players published by De Groot in the 1960s helped to uncover this relationship. Chess masters and weekend players demonstrate comparable general problem-solving skills. When shown a board configuration for five seconds from a real game and then asked to reproduce that configuration on a new board, chess masters were able to reproduce the board with $70 \%$ accuracy compared with 30\% accuracy for amateur players. Yet, when random board configurations were used, both groups performed equally poorly. Masters were only superior on configurations taken from real games (Chase \& Simon 1973; Sweller \& van Merrienboer 2013). These results have been replicated in a variety of other areas, including baseball (Chiesi et al. 1979), electronics (Egan \& Schwartz 1979) and algebra (Sweller \& Cooper 1985). It can take years and thousands of hours of practice to obtain the knowledge associated with high levels of problem-solving skills (Ericsson \& Charness 1994). To use the computer analogy from above, the seven documents that experts are able to open in WM have much more information that is of higher quality and better organized than non-experts.

\section{Cognitive load and CLT}

Although schemata are stored in LTM, their construction and refinement occurs in WM. CLT was initially developed by John Sweller in the 1980s (Sweller 1988). As described above, CLT starts with the premise that each learner has limited WM. This premise has important implications for instructional design. Because learning requires the processing of information in WM, learning suffers when the cognitive load of the task exceeds the WM capacity of the trainee. Therefore, CLT prioritizes optimizing information processing in WM. CLT identifies three types of cognitive load:

(1) Intrinsic load-load associated with the task.

(2) Extraneous load-load not essential to the task.
(3) Germane load-load imposed by the learner's deliberate use of cognitive strategies to reorganize information to make it suitable for storage in LTM, i.e. to learn.

CLT has used this understanding of WM to test and develop instructional techniques that optimize cognitive load, and, thereby, facilitate learning. CLT has also been further developed to support the understanding of complex learning, i.e. where the actual doing of authentic, "real world" activities is used to drive the simultaneous development of skills, knowledge and attitudes (van Merriënboer \& Sweller 2005; van Merriënboer \& Kirschner 2013). More recently, CLT has been used as an explanation of performance (as opposed to learning) (La Rochelle et al. 2011).

\section{Intrinsic cognitive load}

The intrinsic load of a task depends on several factors: the proficiency of the individual, the number of information elements and the extent to which the elements associated with the task interact with each other (referred to as element interactivity). Intrinsic load increases with the number of information elements-learning the diagnostic criterion for four diseases requires more WM than two. Intrinsic load also increases as the information elements become less isolated or independent of one another, i.e. interact more with each other. As the number of items in WM increases linearly, the number of possible interactions (i.e. combinations) increases exponentially. This makes trial and error (or random) testing of possible combinations effectively impossible when there is a high degree of interactivity. An example from Anatomy and Physiology can illustrate this. Learning the anatomy of the heart, including the four chambers, the septum, the valves, etc., has relatively low element interactivity, i.e. the names of structures do not change due to interactions between the parts. In contrast, learning about cardiac output has much higher element interactivity-preload, afterload and contractility (three information elements) interact to determine stroke volume (another information element), which in turn interacts with heart rate (yet another element) to determine cardiac output. A change in one factor (such as preload) will influence other factors (such as stroke volume). The higher degree of interactivity increases the intrinsic load.

The intrinsic load imposed by element interactivity can be modulated by the learner's expertise (i.e. the availability and automaticity of their schemata). When a more advanced learner already possesses a schema that incorporates some or all of the interacting elements into a single element (e.g. the construct of stroke volume, which then entails the three elements of preload, afterload and contractility), the intrinsic load of that learning task is reduced. Therefore, intrinsic load generated by a task cannot be altered by instructional interventions without either simplifying the task to be learned or first enhancing the expertise of the learners by providing preparatory training prior to the task.

\section{Extraneous cognitive load}

Extraneous load refers to the load imposed upon the trainee's WM but not necessary for learning the task at hand, i.e. for schemata construction or automation. CLT emphasizes how 
instructional techniques can inadvertently impose extraneous load by, for example, providing insufficient guidance and thereby forcing learners to employ weak problem-solving methods such as trial and error or to search for information needed to complete the task. Similarly, when information necessary for learning is distributed in space (e.g. requiring multiple textbooks or with the physical separation of the written text from the accompanying pictures) or time (e.g. across different lectures), scarce WM resources are used to search for the information and bring it together. A teacher provides visual overload when he shows full text slides but allows too little time for the learners to read them; if, in addition, he gives simultaneous verbal information that does not align with the (visual) slides, distracting (extraneous) cognitive load is introduced that will impair both channels of information. Extraneous load arises when information that is too much for either the visual or auditory channel alone is presented via one modality (e.g. only visual or auditory) rather than being distributed appropriately between two (e.g. visual diagram and auditory (spoken words) or when the information in both channels does not align. Finally, distractions not related to the task (e.g. the intern's pager beeping during a lumbar puncture or a colleague interrupting during a handover) impose extraneous load.

Importantly, intrinsic and extraneous load are additive. Extraneous load interferes with learning if the intrinsic load for the task is high for that particular learner. If the task-associated intrinsic load is low, then the extraneous load may not harm learning as long as the total load remains within the learner's WM limitations (Carlson et al. 2003).

\section{Germane cognitive load}

Germane load refers to the load imposed by the mental processes necessary for learning (such as schemata formation and automation) to occur. There is some debate as to whether germane load constitutes its own category or is best understood as a constituent of intrinsic load. We conceptualize germane load as representing the effort associated with learning that is separate and in addition to the effort associated with holding the relevant interacting elements in WM, i.e. the intrinsic load of performing the task. Put simply, germane load can be viewed as the learner's level of concentration devoted to learning (as opposed to performing the task). Germane load is regulated by the individual. When the extraneous and/or intrinsic load are too high and approach or exceed the learner's WM limits, there will be insufficient WM resources available for the germane load necessary for learning (e.g. combining the new information elements with already existing schemata in LTM).

Figure 3 shows how a novice and advanced trainee will experience the same task differently with respect to cognitive load. In all three scenarios, extraneous load is the same. For the novice (Figure 3A), the task is complex and requires more effort merely to execute. The intrinsic load caused by the task is high for this learner, who's WM will become easily overwhelmed, leaving no WM resources for learning (germane load) and, in this case, insufficient WM for the task itself. Figure 3(B) illustrates the principal difference between
(A) Cognitive load of an early learner performing the task

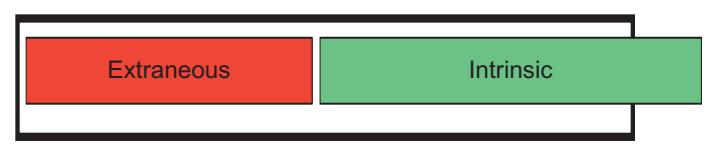

(B) Cognitive load of an advanced learner performing the task with no intention to learn

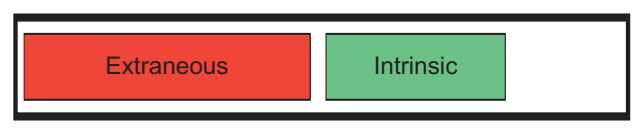

(C) Cognitive load of an advanced learner performing the task and learning

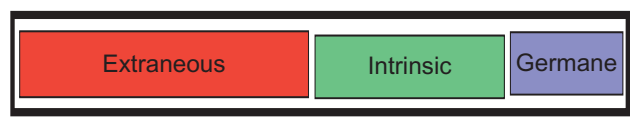

Figure 3. The composition of cognitive load in early and advanced learners performing a similar task.

the novice and advanced trainee. Because of the advanced trainee capacity to retrieve already developed schemata from LTM, performing the task is not complex and requires little concentration. It imposes much less intrinsic load. Clearly, there is no intention to learn. This happens when intermediates do not show deliberate practice or intention to further improve their ability, but just act routinely. Theoretically, however, there is unused WM space that can be allocated to learning (germane load) as is shown in Figure 3(C).

\section{Measuring cognitive load}

As a result of organizing knowledge elements into a cognitive schema which can then be treated as one element in WM, an identical task may surpass the WM capacity in one learner but not in a more skilled other learner. It is therefore important to account for the interaction between the cognitive load imposed by a given task and the learner's level of competence and the quality of her schemata at that time. The concept of "mental effort" does this by representing the proportion of a learner's WM capacity that is allocated to a given task. Mental effort varies directly with cognitive load and inversely with freely available cognitive capacity. A number of measurement techniques have been tested, including learner self-rating of effort (during the task) or difficulty (after the task), response time to a secondary task presented during the task, performance (e.g. number of errors per task) and psychophysiological measures (e.g. heart rate variability or electrical skin conductance; van Merriënboer \& Sweller 2005; DeLeeuw \& Mayer 2008). Learner self-rating has been the most commonly used strategy because it is inexpensive and has established validity (Paas et al. 2003). Moreover, self-rating instruments have recently been developed that aim to measure not only overall cognitive load but also intrinsic (e.g. rate the complexity of the topic covered in the activity), extraneous (e.g. rate the clarity of the instruction for the activity) and germane (e.g. rate how much the activity enhanced your understanding of the topic) load separately (DeLeeuw \& Mayer 2008; Leppink et al. 2013). CLT researchers have also developed measures of the quality 
of the available schemata, a critical determinant of how much of WM's resources will be allocated for a given task (Kalyuga 2009).

\section{CLT and the learning processes}

CLT is applicable to all activities in life that involve executing tasks, but has been mostly studied in the setting of education. As already discussed, CLT focuses on the management of WM during learning. The two major learning processes are schemata construction and automation. Learners construct schemata (also referred to as scripts) during knowledge acquisition and problem-solving by combining and re-combining elements together into larger and more refined chunks. Several cognitive processes facilitate this process, including the following: (1) activating prior knowledge; (2) comparing new information with what they already know; and (3) elaborating knowledge, i.e. incorporating new elements into schemata already stored in LTM or obtaining already schematized information from other people such as supervisors or peers (Taylor \& Hamdy 2013).

With extensive practice, a schema can become fully automated and can act as a central processor, organizing information and knowledge without conscious effort, and, therefore, without burdening WM. With automation, familiar tasks are performed accurately and fluidly, whereas unfamiliar tasks-that require a combination of automated and nonautomated processes - can be learned with maximum efficiency because WM is fully available (Sweller et al. 1998). Without schemata automation, a previously encountered task will not be performed more efficiently the next time. In addition, entirely new tasks may be impossible to complete until prerequisite skills have been automated (van Merriënboer \& Sweller 2005).

Examples of full or near automation include riding a bike, answering "what is 1 plus 1?", instinctively releasing the accelerator and pressing the brake pedal when a car driver sees the brake lights of the cars in front light up or when an experienced clinician seamlessly performs a physical exam. An expert violinist playing one of the major scales is another example. By contrast, when dealing with novel information for which no schemata-based central executive is available, the limitations of WM become relevant. The young violinist can only concentrate on getting the pitch right, if he or she is no longer distracted by maintaining the right position on the string. In both of these processes, learning requires the ability to organize information in WM into schemata, store those schemata in LTM and then retrieve the relevant schemata from LTM into WM when needed. It is clear to anyone seeing a professional violin player perform that it would be impossible for the player to consciously think of all muscle movements and hand positions on the strings while performing a piece. For novices, each of these initially requires slow conscious practice before automation takes place. In fact, while automations may occur more or less "suddenly", it is typically an extremely slow process (Newell et al. 1981; Palmeri 1999).

\section{Synergies with other learning perspectives}

There are, of course, numerous theories of learning. A number of these other perspectives complement CLT and help us develop a broader view of learning. We briefly describe the following theories: situated cognition, self-regulation and emotion and motivation theories. These theories argue that familiarity with the task and the schema(ta) activated (i.e. chunking) are critical elements of cognitive load but do not provide a complete view of cognitive load in a given situation.

Situated cognition argues that thinking is "situated" or nested in the specifics of the encounter (Brown et al. 1989). In other words, participants other than the learner (e.g. in a clinical setting, the patient and perhaps the nurse and/or the attending) and the environment (e.g. ambulatory or inpatient) influence and interact with the learner. From this perspective, the physician's cognitive reserve (load) is influenced by these participant and encounter factors. The greater the number of elements and their interactivity, the greater the expected impact on cognitive load.

Similar to situated cognition, self-regulation argues for an emergent result (outcome) based on a variety of interactive elements (Cleary \& Zimmerman 2001). Self-regulation divides performance into three phases: forethought (before), performance (during) and reflection (after) phases. As such, cognitive load is influenced by the varying cognitive demands of these three interactive phases. For example, one's effort during a task in the form of metacognitive monitoring impacts cognitive load by increasing germane load.

Motivation and emotion have received more attention in medical education research in recent years (Ten Cate et al. 2011). Studies outside of medicine have shown that motivation and emotion influence learning and cognitive performance. Theories in this field include control value theory and selfdetermination theory (Ryan \& Deci 2000). For example, activating emotions, such as enjoyment, have been associated with deep processing, enhanced learning and performance while negative emotions (i.e. anxiety) have been associated with more superficial processing and can impede learning. Thus, motivation and emotion, according to these theories, influence one's cognitive capacity (cognitive load) with activating emotions potentially expanding one's cognitive reserve while inhibiting emotions would be expected to reduce one's cognitive reserve.

\section{CLT, clinical reasoning and the development of medical expertise}

Medical expertise, as with expertise in general, can only be developed over time. Becoming an expert requires knowledge acquisition and experience applying that knowledge. Experts, compared with non-experts, generate superior solutions to problems, perceive and recognize cues that others do not perceive, analyze problems qualitatively, show more accurate self-monitoring, choose better problem-solving strategies, opportunistically use available information and spend less cognitive effort (Chi 2006). In the course of their life, experts 
have built an elaborate LTM in their professional domain, with efficient chunks, schemata or scripts and have used these pathways to arrive at solutions on a regular basis, which in turn enhances their ease of retrieval (Ericsson 2006).

Expert clinical reasoning utilizes two modes of thinking: a rapid generation of ideas that appear as recognized patterns and a slow analytic reasoning process (Eva 2005). For routine problems, and for very experienced experts, pattern recognition is dominant and leads to correct solutions most of the time. Novel problems, on the other hand, require analytic reasoning. Novices cannot adequately recognize patterns and draw conclusions based upon them; doing this leads to guessing. They must always use analytic reasoning. Nobel prize winner Kahnemann has named these two modes: System 1 thinking for the rapid pattern recognition and System 2 thinking for the slow analytic reasoning (Kahneman 2011). Other system models make this same distinction between automatic processing, which is fast, unconscious, inflexible and intuitive because it uses mental shortcuts (System 1), and controlled processing, which is slow, conscious, flexible and effortful (System 2)(Shiffrin \& Schneider 1977; Kahneman 2011). Importantly, Systems 1 and 2 not only work in parallel but also interact with each other. In particular, System 2 can be employed to monitor the quality of the answers provided by System 1; and if it is convinced that our intuition is wrong, then it is capable of correcting or overriding the automatic judgments. Novices and experts thus differ from each other in both System 1 and 2 processing.

Van Merriënboer (2013) describes the implications of System 1-System 2 models for training complex skills such as clinical reasoning (van Merriënboer 1997, 2013; van Merriënboer \& Kirschner 2013). First, it is clear that practice aimed at the development of such skills must attend to the development of both Systems 1 and 2 processing, and that learners must also learn to co-ordinate both types of processing. In other words, practice must aim at the development of routine aspects of behavior as well as the development of nonroutine aspects of behavior, such as conscious reasoning (i.e. use of domain knowledge to infer tentative problem solutions) and conscious decision-making (i.e. use of cognitive strategies to approach problems in a systematic fashion). For a novice learner, those aspects that need to be developed into System 1 behaviors are called recurrent skills (van Merriënboer 1997); they are treated as being consistent from problem situation to problem situation. Critical to the development of recurrent skills is repetitive practice. For example, after vast amounts of repetitive practice, pathologists become expert microscope users because they have developed cognitive rules that drive particular actions under particular circumstances - their finger movements to zoom in, zoom out, and position the slide are directly (unconsciously) driven by System 1 regardless of whether the slide is showing infectious, vascular, nutritional or other injuries. Repetitive practice also yields cognitive expertise; for example, the ability to immediately distinguish normal from abnormal tissue. In contrast, those aspects that need to be developed into non-routine, System 2 behaviors are called non-recurrent skills; these behaviors differ from problem situation to problem situation. Critical to the development of non-recurrent skills is variability of practice (Paas \& Van
Merrienboer 1994), meaning that learners should practice on problems that differ in the same dimensions as in the real world. For example, only after seeing bipolar illness or pneumonia in multiple settings and scenarios do physicians become adept at modifying their diagnostic and treatment strategies to the various (typical and atypical) presentations of those illnesses.

Complex skills such as clinical reasoning develop over time as a function of practice. According to traditional phase models (Dreyfus \& Dreyfus 1980), an expert would simply be described as someone who has automated most of his or her task performance. CLT, however, is more in line with System models according to which experts not only differ from novices in that they have automated many routine aspects of tasks (i.e. superior System 1 functioning), but their deep understanding of the domain (i.e. in rich cognitive schemata) also allows them to recognize and interpret new problem situations in more general terms, to monitor and to reflect on the quality of their own performance and to detect and correct errors (i.e. superior System 2 functioning).

The dual reasoning systems model in clinical reasoning has recently been critiqued and the cognitive continuum theory has been proposed as an alternative (Custers 2013). This perspective argues that mental processing does not consist of two distinct modes (either one or the other). Rather mental processing occurs along a continuum, with System 1 and System 2 representing the two poles. Furthermore, cognitive continuum theory argues that most clinical situations require a mode of thinking somewhere in between pure System 1 (intuitive) or System 2 (rational) thinking, i.e. a form of quasirational thinking. From an educational point of view, the task is to prepare trainees to move between these modes effectively and appropriately, whether these modes represent dual systems or lie upon a continuum.

"Encapsulation" has been proposed as the mechanism by which schemata are automated and effective System 1 thinking emerges (Boshuizen \& Schmidt 1992; Schmidt \& Boshuizen 1993). Studies on novices, intermediate learners and experts demonstrate that biomedical knowledge is efficiently stored in LTM, but that increasing levels of expertise are associated with less conscious application of that knowledge. That knowledge, however, has not been forgotten (erased) but rather embedded within more elaborate schemata. These schemata in clinical medicine that constitute the chunks of encapsulated knowledge in LTM have been called "illness scripts". Illness scripts include three features of a disease entity: causal factors and etiology (called "enabling factors"), physical disease mechanism ("fault") and the resulting signs, symptoms and prognosis ("consequences") (Feltovich \& Barrows 1984; Schmidt \& Boshuizen 1993; Custers et al. 1998). When necessary, illness scripts and the embedded biomedical knowledge can be unpacked and the elements used separately. In terms of memory architecture, the expert deals with familiar clinical situations stored as illness scripts in LTM as single units in the WM, only to be de-capsulated when something unfamiliar happens. This frees much of the WM to enable the processing of other information.

The lesson for the teaching of clinical reasoning is that starting with studying complete (whole-task) cases that are 
relatively simple, thus, not necessarily "authentic", can help with building rough illness scripts that can be refined later. By repeatedly analyzing cases with relatively few features, students eventually develop the ability to intuitively recognize groups of features that are caused by the same disease (Custers 2013). With this foundation, students may enter the clinical environment and experience the subtle differences in cases that enable refinement.

\section{CLT and instructional design}

Medical education is in reality a continuum of activities that spans undergraduate medical education, graduate medical education and continuing medical education. CLT provides a framework for the design and implementation of these activities. In particular, CLT contends that we can best facilitate learning (schemata construction and automation) by regulating cognitive load via three strategies:

- Decrease of extraneous load (e.g. of interruptions).

- Management of intrinsic load (e.g. simplifying tasks if necessary).

- Optimization of germane load (e.g. encouragement of the use of cognitive strategies that facilitate schemata construction).

In addition, CLT research has identified the expertisereversal effect-a phenomenon in which the instructional techniques helpful to early learners (e.g. decreasing extraneous load or simplifying the task) are not helpful to experts and can even result in worse performance (van Merriënboer \& Sweller 2010). Although many examples of the expertisereversal effect have been reported in the literature (Kalyuga 2007), the use of worked examples and conventional problems provides a good illustration. Novice learners can only solve conventional problems through weak-method problem solving (e.g. means-ends analysis) which, in turn, impose a high extraneous cognitive load and do not help novice learners to construct cognitive schemas in LTM. Thus, novice learners learn more from studying worked examples than from solving the equivalent problems. For more advanced learners, worked examples become superfluous because they have already developed useful schemas in LTM. The presentation of worked examples may even interfere with the schemas they have available in memory. Thus, in contrast to novice learners, more advanced learners learn more from solving conventional problems than from studying the equivalent worked examples. Learning how to complete a history provides another example. To assist early learners in medicine, mnemonic aids are often used to facilitate recall such as "OPQRST" for characterizing chest pain (onset, provocation, quality, radiation, severity and timing). These mnemonics can be extremely helpful when students face their first clinical encounters, but do not help experienced physicians. Use of these acronyms can in fact slow down their practice.

CLT has particular relevance to medical education in the clinical workplace because the tasks and professional activities to be learned require the simultaneous integration of multiple and varied sets of knowledge, skills, and behaviors at a specific time and place. These activities possess high element interactivity and therefore impose a cognitive load that may surpass the WM capacity of the learner. A specific approach when the learning tasks at hand are complex is to provide scaffolds (worked examples are often recommended) and to simplify tasks without de-contextualizing them (whole-task approaches are often recommended). When a task is very complex, peer collaboration has been recommended to alleviate individual cognitive load (Schunk 2012). This may imply that learners within a group would divide parts of the task among themselves.

Based on CLT, instructional approaches that have been proposed are whole-task approaches, the elaborate fourcomponent instructional design (4C/ID) approach that is consistent with both CLT and System 1-System 2 theory and numerous empirically derived instructional techniques. All apply to what has been called "complex learning", i.e. the learning of real life tasks that cannot easily be mastered and require instruction and practice before they are mastered.

\section{Whole-task training approaches}

A major problem that particularly vocational and professional education struggles with is transfer. Too often employers or supervisors and students themselves complain that they as graduates are not sufficiently prepared to act in the workplace, despite educational programs that have covered all relevant topics. Learners are said to be not able to transfer what has been "learned" in school to what they must "do" at work (Konkola et al. 2007). One reason for this is that the educational programs decompose the real life tasks into fragments that are taught at different moments in the curriculum. The acknowledged need to integrate the teaching of similar topics (e.g. heart) from different disciplines (e.g. physiology, pathology, pharmacology) and courses has led to horizontally and vertically integrated curricula (O'Neill et al. 2000), but the whole-task approach goes a step further. To understand the problem of fragmentation in terms of the WM, transfer requires the retrieval and combination of too many separate elements from the LTM. The WM simply cannot combine all these elements and even more so under time and other pressures of the working environment. The learner lacks the bigger chunks, stored in the LTM, that constitute the combinations of the required elements. Think of specific declarative (what to do) and procedural (how to do it) knowledge, together with psychomotor skill and with the right attitude or context sensitivity that are all necessary to perform the task in real life. Whole-task training approaches are holistic in the sense that from the start all of these are combined and resemble the real life situation.

Several innovations in medical education over the past decades employ a whole task approach and may be successful because of their effect on the regulation of WM processes. Problem-based learning is such a holistic approach (Dolmans et al. 2013), as are horizontal integration (Harden et al. 1984) and vertical integration (Wijnen-Meijer et al. 2010). A recent discussion about the risk of fragmentation of medical competencies by applying a competency-based approach (Grant 1999; Lurie et al. 2009) has led to the concept of entrustable professional activities, a more holistic framework 
Table 1. Summary of the four components instructional design approach to medical education.

\begin{tabular}{|c|c|c|}
\hline Component & Aims at & Instructional techniques \\
\hline 2. Supportive information & $\begin{array}{l}\text { Schema construction for non-recurrent } \\
\text { aspects of the whole task }\end{array}$ & $\begin{array}{l}\text { - Simple-to-complex sequencing of learning tasks based on authentic, } \\
\text { real-life tasks } \\
\text { - Variability of practice } \\
\text { - Decreasing support and guidance at each level of complexity } \\
\text { - Explain how to systematically approach tasks in the domain and how } \\
\text { the domain is organized } \\
\text { - Promote elaboration of new information through self-explanation, } \\
\text { questioning, group discussion, etc. } \\
\text { - Promote reflection through cognitive feedback }\end{array}$ \\
\hline 3. Procedural information & $\begin{array}{l}\text { Schema automation for recurrent aspects } \\
\text { of the whole task }\end{array}$ & $\begin{array}{l}\text { - Tell how to perform routine aspects of the task (how-to instructions) } \\
\text { - Promote the formation of automated schemas through providing just-in- } \\
\text { time instructions precisely when learners need them during whole-task } \\
\text { performance } \\
\text { - Promote learning of routines through corrective and immediate feedback }\end{array}$ \\
\hline 4. Part-task practice & & - Provide repetitive practice for selected routine aspects of the whole task \\
\hline
\end{tabular}

for clinical training and assessment (ten Cate 2005; ten Cate \& Scheele 2007; Pangaro \& ten Cate 2013). Curriculum designers in medicine struggle with the requirements to include an ever expanding knowledge base. The traditional and all too common solution of granting many experts space so that each may add small contributions leads to fragmentation and transfer problems. Another example is the scheduling of short clerkships, i.e. one or two or four weeks (Holmboe et al. 2011). As a reaction, longitudinal clerkships (up to one year) are being proposed (Hirsh et al. 2012).

Lengthening clinical attachments to allow for time to digest stimuli and establish coherence in the LTM is one way. Another option is to narrow down clinical experiences to a small domain, but intensify the work and responsibility in that domain. It is remarkable how well junior students are able to grasp enough of the ins and outs of those tasks to practice at a high level in patient care (Chen et al. 2014).

\section{The 4C/ID approach}

An elaborate instructional model that fully aligns with CLT is the 4C/ID approach to complex learning (van Merriënboer \& Kirschner 2013). The four components (see Table 1 for a summary) focus on the specification of the following:

(1) A series of learning tasks. These should be holistic, integrated tasks authentically resembling vocational or professional practice. The series consists of tasks that increase in complexity. If the task were a patient consultation, the simple version would be a patient who communicates well, with a single question, a clear disease that requires a routine approach for diagnosis and treatment and has excellent prognosis. The complex case would be a patient with impaired communication ability, with multiple seemingly unrelated signs and symptoms, which requires elaborate investigations that may end in differential critical diagnoses with difficult treatment and suboptimal prognosis.

(2) Supportive information that is typically studied by the learner before the task requires this information. This information can be specific content information to guide a thinking step (e.g. information about the adverse effects of specific medications when anticipating a consultation of a known patient), as the information is not (yet) present and retrievable from LTM. Supportive information is relevant for the development of nonrecurrent aspects of a task (System 2) and can be seen as scaffolding that should be reduced in the course of skill acquisition at one particular level of complexity. Supportive information usually has high element interactivity, which makes it less useful to be presented during the task execution.

(3) Procedural information telling the trainee what to do, step by step. It is relevant for the development of recurrent aspects of a task (System 1). As it provides little element interactivity, it can best be presented during the task, exactly when the learner needs it. Procedural information includes direct feedback information about the task execution. A clinical supervisor could provide this information.

(4) Part-task learning opportunities to rehearse and store chunks in LTM that enable gearing at higher complexity levels in subsequent tasks. One should be careful to apply part-task rehearsals as they should not become standalone learning tasks, but in some cases, it is very helpful to practice subtasks. In surgical specialties, suturing is evidently a part-task that can be well practiced separately.

The 4C/ID approach has been elaborated into a 10-step procedure in a book that provides many more details (van Merriënboer and Kirschner 2013).

\section{CLT-derived instructional techniques}

CLT researchers have used their model of learning to generate and test a number of instructional techniques aimed at managing cognitive load (Sweller 2005; Plass et al. 2010; Sweller et al. 2011; Sweller \& van Merrienboer 2013). Table 2 describes a number of these techniques and how they might apply to medical education. The techniques are organized by the four principal instruction strategies of CLT: minimize extraneous load; manage intrinsic load when 


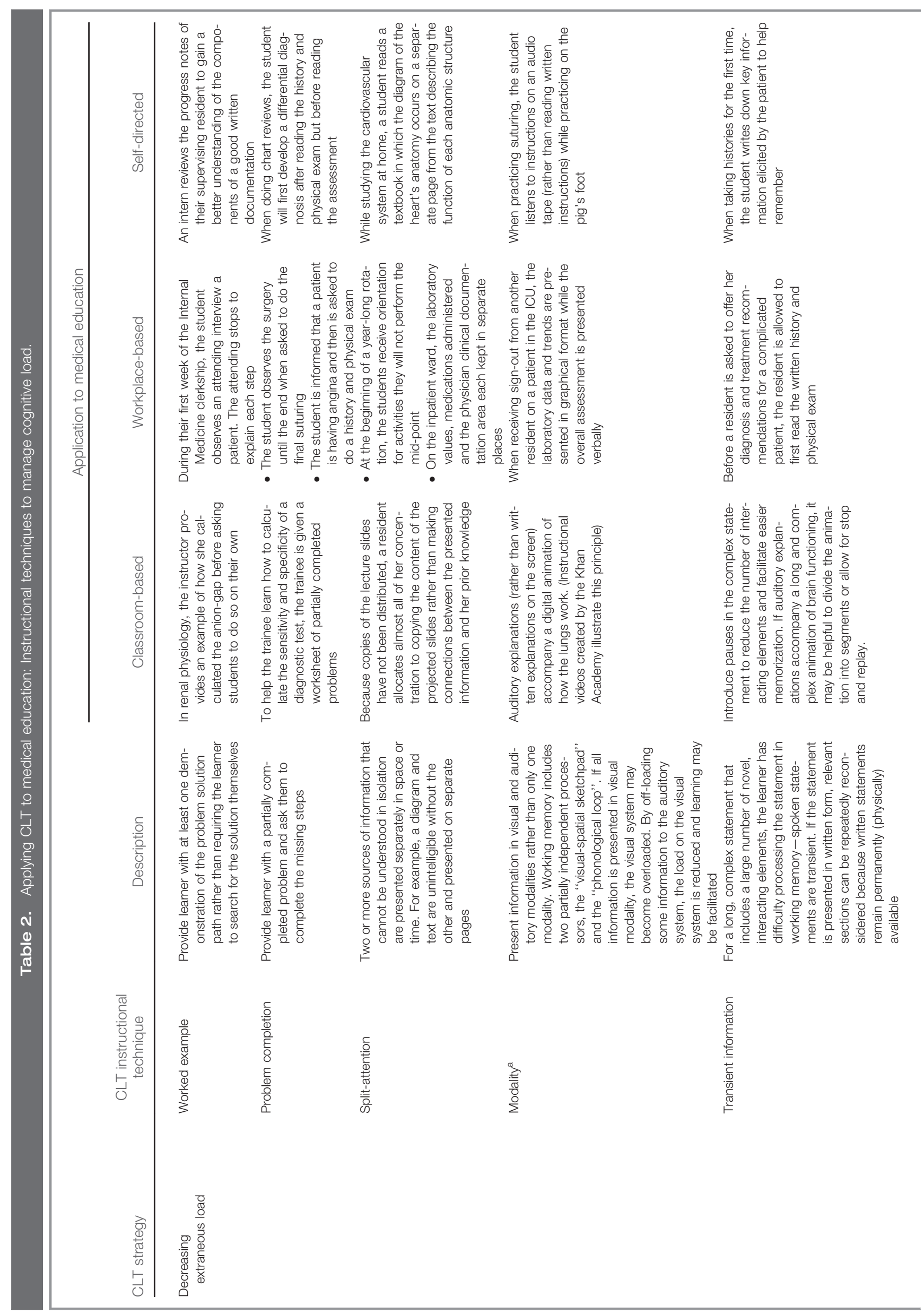




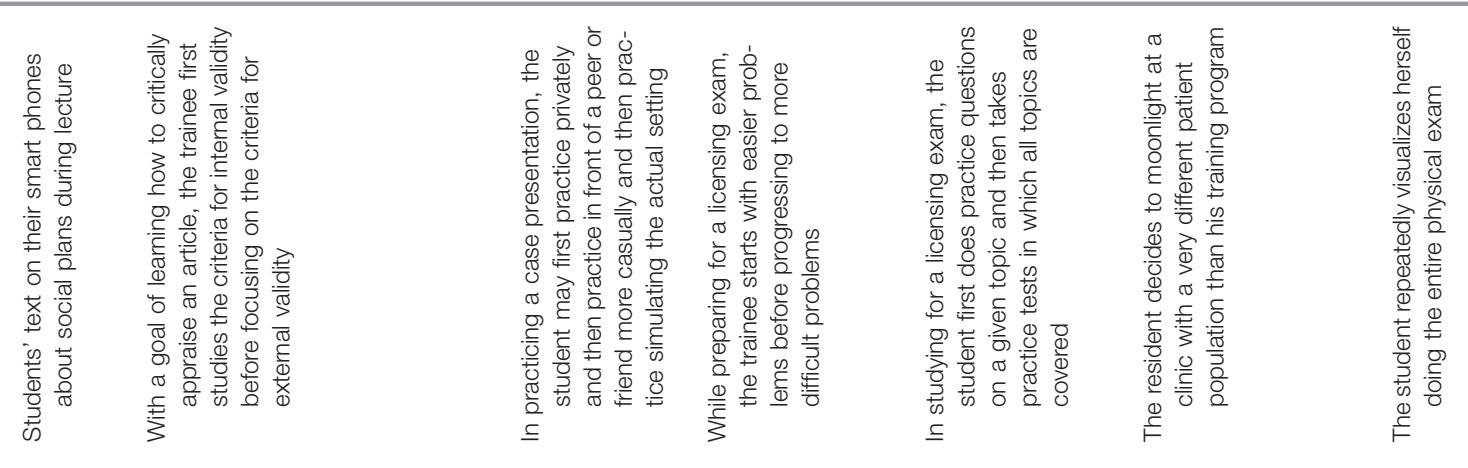

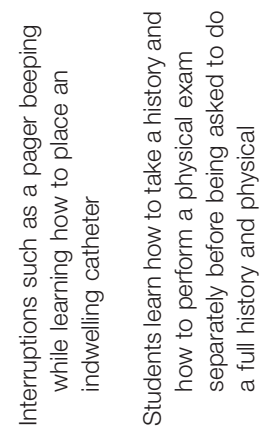

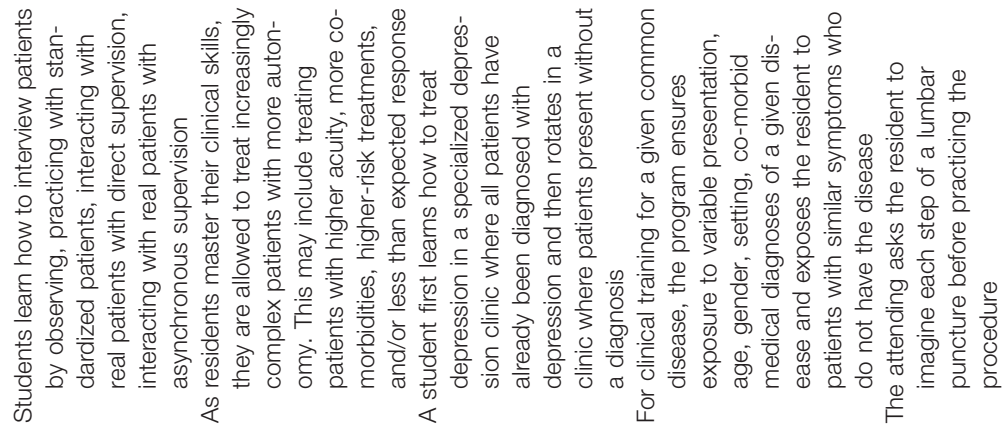

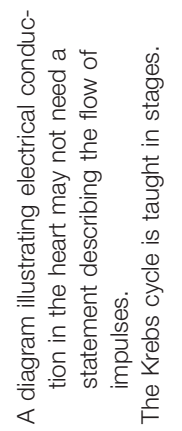
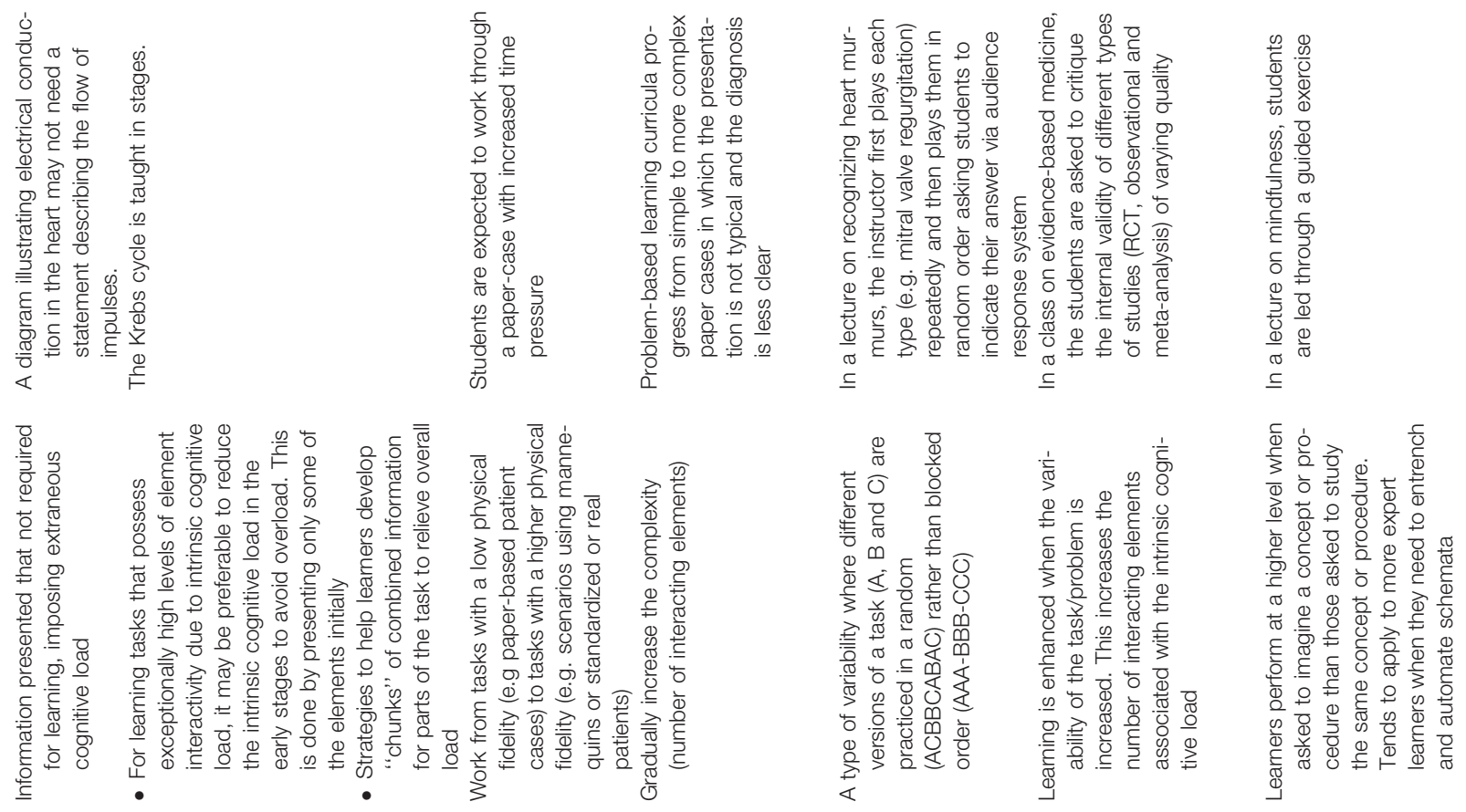

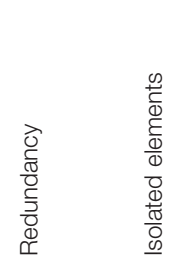
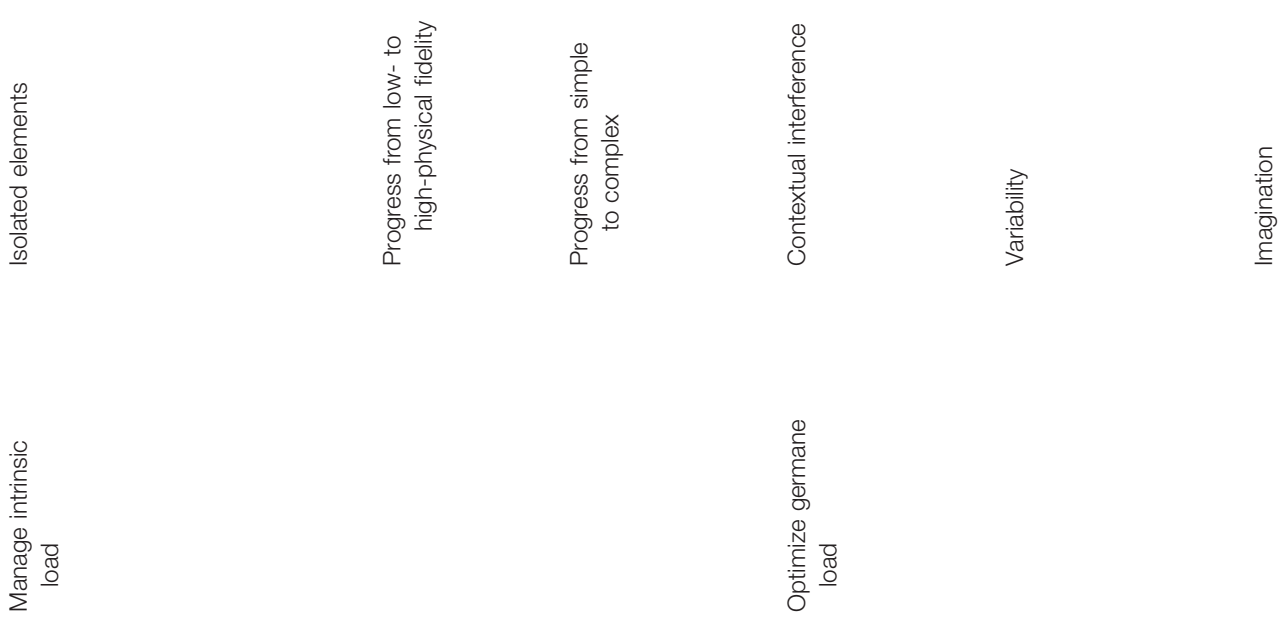


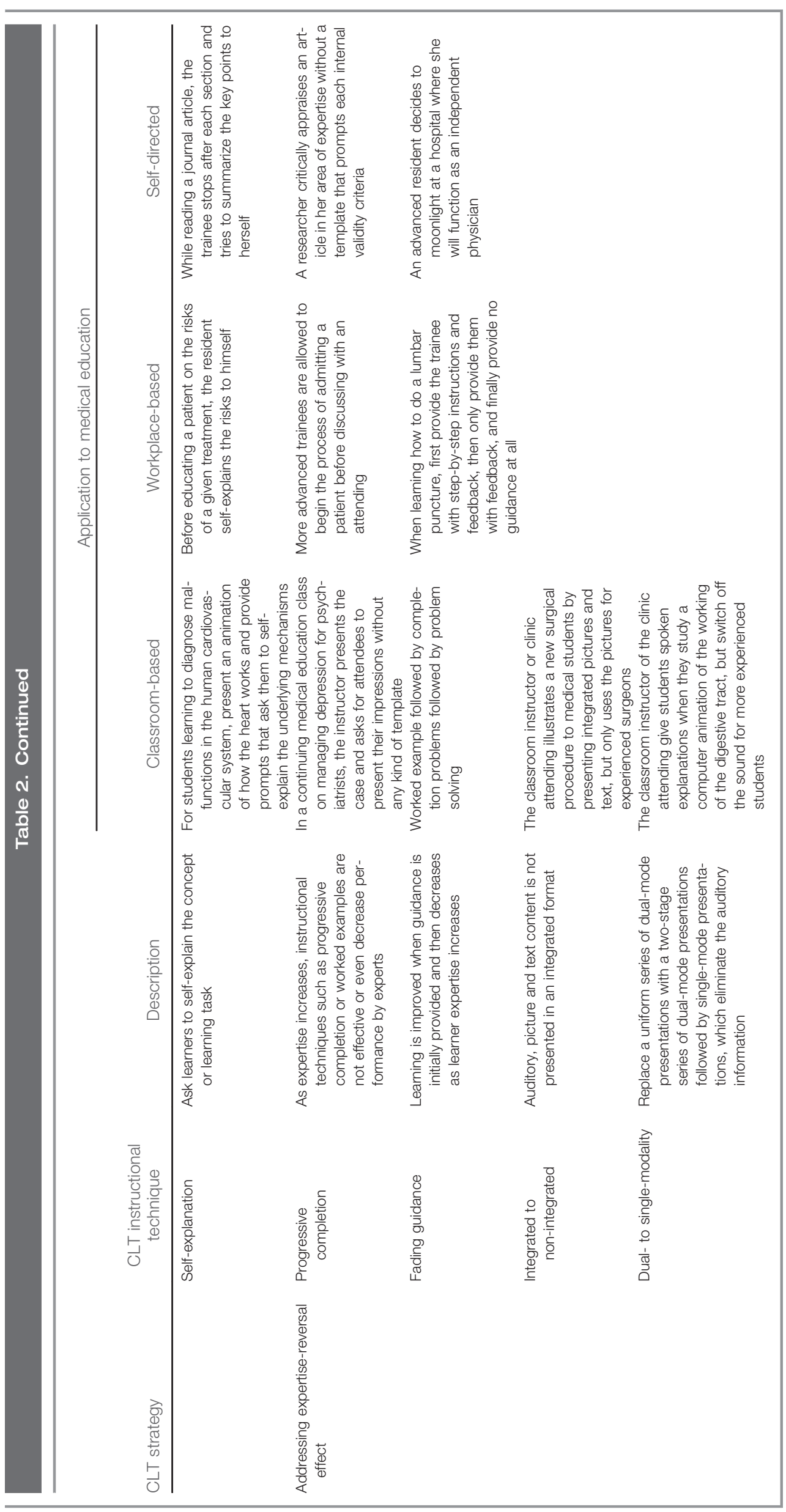


necessary; optimize germane load; and address the expertisereversal effect. Examples are given for each of these strategies for three different types of instructional settings: class-room, workplace and self-directed learning. Most of these instructional techniques have been empirically tested and proved to be effective in multiple studies.

\section{Conclusion}

CLT builds upon a cognitive architecture that includes a model of human memory (sensory, working, and long-term) and assumptions about how learning occurs (schemata construction that is refined in WM and may then be encoded and automated in LTM via conscious practice). The theory draws attention to how WM, with its limited capacity, represents a "bottleneck" in the formation of LTM (or learning). Therefore, it focuses on strategies to optimize WM. CLT has identified three types of cognitive load that impact WM: extraneous, intrinsic and germane. Instructional techniques derived from CLT focus on reducing extraneous load. If the task demands still exceed the learners WM, then the intrinsic load should be reduced (by, e.g. simplification of the whole-task or, if necessary, starting with part-tasks). As the extraneous load is minimized and the intrinsic load is titrated to the developmental stage of the learner, instructional techniques must also seek to ensure that learners use the freed up WM capacity for learning by increasing germane load. A number of instructional techniques have been developed and empirically tested. Importantly, as learners' progress, curricula must also attend to the expertise-reversal effect.

CLT offers a framework and a rich set of tools with which to design instruction. Its application to medical education is relatively new. Future research will need to identify which instructional techniques are most effective at managing cognitive load in the setting of medical education and how these techniques interact with the developmental stage of the trainee. Future research will also need to determine how best to simplify and sequence "whole-tasks" for the early learner and then how to address the expertise-reversal effect for the more advanced learner. Developing valid methods for measuring cognitive load and its components will be critical to testing both the applicability of the theory and the efficacy of techniques derived from the theory.

\section{Notes on Contributors}

JOHN Q. YOUNG, MD, MPP, is the Vice Chair for Education in the Department of Psychiatry at Hofstra North Shore-LIJ School of Medicine and The Zucker Hillside Hospital.

JEROEN VAN MERRIENBOER, PhD, is a Professor of Learning and Instruction in the Department of Educational Development and Research, Faculty of Health, Medicine and Life Sciences, Maastricht University. He is the Program Director of Research in Education, School of Health Professions Education.

STEVEN DURNING, MD, PhD, is a Professor of Medicine and Pathology at the Uniformed Services University (USU). He directs the Introduction to Clinical Reasoning Course and is a general internist.

OLLE TEN CATE, PhD, is a Professor of Medical Education and Director of the Center for Research \& Development of Education at the University Medical Center Utrecht, the Netherlands.
Declaration of interest: The authors report no conflicts of interest. The authors alone are responsible for the content and writing of the article.

\section{References}

Atkinson RC, Shiffrin RM. 1968. Human memory: A proposed system and its control processes. In: Spence KW, Taylor Spence J, editors. Psychology of learning and motivation. New York: Academic Press, 89-195.

Boshuizen HP, Schmidt HG. 1992. On the role of biomedical knowledge in clinical reasoning by experts, intermediates and novices. Cogn Sci 16: 153-184.

Bowen JL. 2006. Educational strategies to promote clinical diagnostic reasoning. N Engl J Med 355:2217-2225.

Brown JS, Collins A, Duguid P. 1989. Situated cognition and the culture of learning. Educ Res 18:32-42.

Carlson R, Chandler P, Sweller J. 2003. Learning and understanding science instructional material. J Educ Psychol 95:629-640.

Chase WG, Simon HA. 1973. Perception in chess. Cogn Psychol 4:55-81.

Chen H, Sheu L, O'Sullivan P, Ten Cate O, Teherani A. 2014. Legitimate workplace roles and activities for early learners: Lessons from studentrun clinics. Med Educ 48(2):136-145.

Chi MTH. 2006. Two approaches to the study of experts' characteristics. In: Ericsson KA, editor. The Cambridge handbook of expertise and expert performance. Cambridge: Cambridge University Press, 21-30.

Chiesi HL, Spilich GJ, Voss JF. 1979. Acquisition of domain-related information in relation to high and low domain knowledge. J Verb Learn Verb Behav 18:257-273.

Cleary TJ, Zimmerman BJ. 2001. Self-regulation differences during athletic practice by experts, non-experts, and novices. J Appl Sport Psychol 13: 185-206.

Custers EJ. 2013. Medical education and cognitive continuum theory: An alternative perspective on medical problem solving and clinical reasoning. Acad Med 88:1074-1080.

Custers EJFM, Boshuizen HPA, Schmidt HG. 1998. The role of illness scripts in the development of medical diagnostic expertise: Results from an interview study. Cogn Instr 16:367-398.

Deleeuw KE, Mayer RE. 2008. A comparison of three measures of cognitive load: Evidence for separable measures of intrinsic, extraneous, and germane load. J Educ Psychol 100:223-234.

Dolmans DH, Wolfhagen IH, Van Merrienboer JJ. 2013. Twelve tips for implementing whole-task curricula: How to make it work. Med Teach 35(10):801-805.

Dreyfus SE, Dreyfus HL. 1980. A five-stage model of the mental activities involved in directed skill acquisition. Washington, DC: Storming Media.

Egan DE, Schwartz BJ. 1979. Chunking in recall of symbolic drawings. Mem Cognit 7:149-158.

Ericsson KA. 2006. The Cambridge handbook of expertise and expert performance. Cambridge, NY: Cambridge University Press.

Ericsson KA, Charness N. 1994. Expert performance: Its structure and acquisition. Am Psychol 49:725-747.

Eva KW. 2005. What every teacher needs to know about clinical reasoning. Med Educ 39:98-106.

Feltovich PJ, Barrows HS. 1984. Issues of generality in medical problem solving. In: Schmidt HG, Volder ML, Learning DISOP-B, editors. Tutorials in problem-based learning: New directions in training for the health professions. Assen, The Netherlands: Van Gorcum, 128-142.

Grant J. 1999. The incapacitating effects of competence: A critique. Adv Health Sci Educ Theory Pract 4: 271-277.

Harden RM, Sowden S, Dunn WR. 1984. Educational strategies in curriculum development: The SPICES model. Med Educ 18:284-297.

Hirsh D, Walters L, Poncelet AN. 2012. Better learning, better doctors, better delivery system: Possibilities from a case study of longitudinal integrated clerkships. Med Teach 34:548-554.

Holmboe E, Ginsburg S, Bernabeo E. 2011. The rotational approach to medical education: Time to confront our assumptions? Med Educ 45: 69-80. 
Issa N, Schuller M, Santacaterina S, Shapiro M, Wang E, Mayer RE, Darosa DA. 2011. Applying multimedia design principles enhances learning in medical education. Med Educ 45:818-826.

Kahneman D. 2011. Thinking, fast and slow. New York: Farrar, Straus and Giroux.

Kalyuga S. 2007. Expertise reversal effect and its implications for learnertailored instruction. Educ Psychol Rev 19:509-539.

Kalyuga S. 2009. Knowledge elaboration: A cognitive load perspective Learn Instr 19:402-410

Kirschner PA, Sweller J, Clark RE. 2006. Why minimal guidance during instruction does not work: An analysis of the failure of constructivist, discovery, problem-based, experiential, and inquiry-based teaching. Educ Psychol 41:75-86.

Konkola R, Tuomi-Gröhn T, Lambert P, Ludvigsen S. 2007. Promoting learning and transfer between school and workplace. J Educ Work 20 211-228.

La Rochelle JS, Durning SJ, Pangaro LN, Artino AR, Van der Vleuten CPM, Schuwirth L. 2011. Authenticity of instruction and student performance: A prospective randomised trial. Med Educ 45:807-817.

Leppink J, Paas F, Van der Vleuten CP, Van Gog T, Van Merrienboer JJ. 2013. Development of an instrument for measuring different types of cognitive load. Behav Res Methods 45(4):1058-1072

Lurie SJ, Mooney CJ, Lyness JM. 2009. Measurement of the general competencies of the accreditation council for graduate medical education: A systematic review. Acad Med 84:301-309.

Mallisena, Dhruva AB. 1933. Syadvadamanjari of Mallisena. Poona: Bhandarkar Oriental Research Institute.

Mayer RE. 2010. Applying the science of learning to medical education. Med Educ 44:543-549.

Miller GA. 1956. The magical number seven, plus or minus two: Some limits on our capacity for processing information. Psychol Rev 63:81-97.

Mousavi SY, Low R, Sweller J. 1995. Reducing cognitive load by mixing auditory and visual presentation modes. J Educ Psychol 87:319-334.

Newell A, Rosenbloom PS, Anderson JR. 1981. Cognitive skills and their acquisition. Hillsdale, NJ: Erlbaum.

Norman GR, Tugwell P, Feightner JW, Muzzin LJ, Jacoby LL. 1985. Knowledge and clinical problem-solving. Med Educ 19:344-356.

O'Neill PA, Morris J, Baxter CM. 2000. Evaluation of an integrated curriculum using problem-based learning in a clinical environment: The Manchester experience. Med Educ 34:222-230.

Paas F, Tuovinen JE, Tabbers H, Van Gerven PWM. 2003. Cognitive load measurement as a means to advance cognitive load theory. Educ Psychol 38:63-71

Paas FGWC, Van Merrienboer JJG. 1994. Variability of worked examples and transfer of geometrical problem-solving skills: A cognitive-load approach. J Educ Psychol 86:122-133.

Paivio A. 1986. Mental representations: A dual coding approach. Oxford Oxford University Press.

Palmeri TJ. 1999. Theories of automaticity and the power law of practice. J Exp Psychol Learn Mem Cogn 25:543-551.

Pangaro L, Ten Cate O. 2013. Frameworks for learner assessment in medicine: AMEE Guide No. 78. Med Teach 35:e1197-e1210.
Plass JL, Moreno R, Brünken R. 2010. Cognitive load theory. Cambridge, NY: Cambridge University Press

Ryan RM, Deci EL. 2000. Self-determination theory and the facilitation of intrinsic motivation, social development, and well-being. Am Psychol 55:68-78.

Schmidt HG, Boshuizen HP. 1993. On acquiring expertise in medicine. Educ Psychol Rev 5:205-221.

Schunk DH. 2012. Learning theories: An educational perspective. Boston: Pearson.

Shiffrin RM, Schneider W. 1977. Controlled and automatic human information processing: II. Perceptual learning, automatic attending and a general theory. Psychol Rev 84:127-190.

Sweller J. 1988. Cognitive load during problem solving: Effects on learning. Cogn Sci 12:257-285.

Sweller J. 2005. Implications of cognitive load theory for multimedia learning. New York, NY: US, Cambridge University Press.

Sweller J, Ayres PL, Kalyuga S. 2011. Cognitive load theory. New York: Springer.

Sweller J, Cooper GA. 1985. The use of worked examples as a substitute for problem solving in learning algebra. Cogn Instr 2:59-89.

Sweller J, Van Merrienboer JJG. 2013. Instructional design for medical education. In: Walsh K, editor. Oxford textbook of medical education. Oxford, UK: Oxford University, 74-85.

Sweller J, Van Merrienboer JJG, Paas FGWC. 1998. Cognitive architecture and instructional design. Educ Psychol Rev 10:251-296.

Taylor DC, Hamdy H. 2013. Adult learning theories: Implications for learning and teaching in medical education: AMEE Guide No. 83. Med Teach 35(11):e1561-e1572.

Ten Cate O. 2005. Entrustability of professional activities and competencybased training. Med Educ 39:1176-1177.

Ten Cate O, Scheele F. 2007. Competency-based postgraduate training: Can we bridge the gap between theory and clinical practice? Acad Med 82: 542-547.

Ten Cate O, Kusurkar RA, Williams GC. 2011. How self-determination theory can assist our understanding of the teaching and learning processes in medical education. AMEE guide No. 59. Med Teach 33:961-973.

Van Merriënboer JJG. 1997. Training complex cognitive skills: A FourComponent Instructional Design model for technical training. Englewood Cliffs, NJ: Educational Technology Publications.

Van Merriënboer JJG. 2013. Perspectives on problem solving and instruction. Comput Educ 64:153-160.

Van Merriënboer JJG, Kirschner P. 2013. Ten steps to complex learning: A systematic approach to four-component instructional design. New York, London: Routledge.

Van Merriënboer JJG, Sweller J. 2005. Cognitive load theory and complex learning: Recent developments and future directions. Educ Psychol Rev 17:147-177.

Van Merriënboer JJG, Sweller J. 2010. Cognitive load theory in health professional education: Design principles and strategies. Med Educ 44: 85-93.

Wijnen-Meijer M, Ten Cate OT, Van der Schaaf M, Borleffs JC. 2010. Vertical integration in medical school: Effect on the transition to postgraduate training. Med Educ 44:272-279. 